\title{
Análise do efeito da colheita da planta de milho em diferentes estádios reprodutivos e do processamento dos grãos sobre a qualidade da silagem ${ }^{1}$
}

\section{Analysis of effect of harvest corn plant in different stages of reproductive and processing of grain on the quality of silage}

\author{
Fabiano Marafon ${ }^{2 *}$; Mikael Neumann ${ }^{3}$; Tânia Mara Becher Ribas ${ }^{4}$; \\ Luan Lucas Reinehr'; Mateus Poczynek ${ }^{4}$; Antonio Vinícius Iank Bueno4; \\ Bruno Fianco ${ }^{4}$
}

\section{Resumo}

\begin{abstract}
O experimento foi conduzido no Núcleo de Produção Animal (NUPRAN) da Universidade Estadual do Centro Oeste (UNICENTRO), com o objetivo de avaliar o efeito da colheita da planta de milho em diferentes estádios reprodutivos e com diferentes processamentos de grãos sobre a digestibilidade da matéria seca, digestibilidade da fibra em detergente neutro e desempenho animal. O delineamento experimental foi inteiramente casualizado, composto por 4 tratamentos com 4 repetições, onde cada repetição constou de uma baia contendo dois novilhos, totalizando 16 unidades experimentais. Durante a confecção da silagem, foram coletadas amostras homogêneas e representativas das plantas picadas, parte destinada a análise bromatológica antes de sofrer fermentação e outra parte foi inserida em silos "bags", acomodando estes no perfil de cada silo, sendo considerados como unidades experimentais. O experimento teve duração de 84 dias após abertura dos silos, sendo 14 dias para adaptação dos animais, seguidos de 4 períodos de 21 dias. Assim, silagens colhidas em estádio de grão pastoso apresentaram melhores valores de digestibilidade in vitro da matéria seca e digestibilidade da fibra em detergente neutro. A utilização da silagem de milho colhida em estádio R5 possibilitou maior desempenho animal com consequente melhor transformação da matéria seca consumida em ganho de peso diário.

Palavras-chave: Consumo de matéria seca, digestibilidade da matéria seca e digestibilidade da fibra em detergente neutro
\end{abstract}

\begin{abstract}
The experiment was conducted at the Department of Animal Production (NUPRAN) State University Midwest (UNICENTRO), with the objective of evaluate the effect of harvesting the maize plant at different reproductive stages and with different grains process on dry matter digestibility, neutral detergent fiber digestibility and animal performance. The experimental design was completely randomized, with four treatments and four replications, where each replication consisted of a pen with two steers, totaling sixteen experimental units. During the silage confection, homogeneous and representative samples from
\end{abstract}

\footnotetext{
1 Parte da Dissertação de Mestrado do primeiro autor.

${ }^{2}$ M.e, Programa de Pós-Graduação em Produção Vegetal, Universidade Estadual do Centro-Oeste, UNICENTRO, Guarapuava, PR. E-mail: fabiano_marafon@hotmail.com

${ }^{3}$ Prof. Dr., Dept ${ }^{\circ}$ de Medicina Veterinária, UNICENTRO, Guarapuava, PR. E-mail: neumann.mikael@hotmail.com

${ }^{4}$ Discentes de Graduação, Curso de Medicina Veterinária, UNICENTRO, Guarapuava, PR. E-mail: taniamarabecherribas@hotmail. com; reinehrllr@hotmail.com; mateus_poc@hotmail.com; vinicius_bueno602@hotmail.com; bruno.fianco@hotmail.com

* Autor para correspondência
} 
processed plants were collected, part intended for chemical analyses and inserted part in "bags" silo, putting these in the profile of each bunker silo, being considered as experimental units. The experiment lasted 84 days after opining de bunker silos, being 14 days for adaption, followed by 4 periods of 21 days. Thus, silage harvested at dough stage showed higher values of in vitro digestibility of dry matter and neutral detergent fiber. The use of corn silage harvested at R5 stage facilitated better animal performance with consequent transformation of dry matter consumed in daily weight gain.

Key words: Dry matter intake, dry matter digestibility and digestibility of neutral detergent fiber

\section{Introdução}

O estádio em que as plantas de milho se encontram no momento da confecção da silagem, pode ter influencia significativa na composição e qualidade do alimento resultante, visto que o teor de matéria seca é o fator que possui maior impacto na qualidade final das silagens de milho (NEUMANN, et al., 2011). A literatura sugere teores entre 30 a $35 \%$ de matéria nas silagens (NUSSIO et al., 1999), no entanto, as recomendações do estádio ideal da colheita da lavoura são frequentemente contestáveis e, nos dias atuais, estão surgindo atenções para um maior teor enérgico no alimento, o que caracteriza a colheita da lavoura em estádio em que a deposição de amido esteja em fase final ou já tenha ocorrido em sua totalidade.

Quando a colheita é realizada em avançado estádio reprodutivo, tornam-se necessário que a colhedora tenha acessórios que permitam maior processamento dos grãos, aumentando a superfície de contato do endosperma, disponibilizando maior quantidades de carboidratos para os microrganismos fermentadores. Apesar de o amido presente nos grãos de milho não ser fonte de carboidratos para os microorganismos no ínicio da fermentação, este acaba sendo disponibilizado ao longo do tempo, devido ao processo conhecido como hidrólise ácida, favorecendo ainda mais a produção de ácidos que diminuim o potencial hidrogeniônico da silagem, promovendo estabilização do material a nível de silo e consequentemente maior preservação dos nutrientes contidos na planta assim como disponibilidade destes, porteriormente, para os microrganismos ruminais, tornando-se um alimento volumoso com alta qualidade.
Com o avanço no ciclo da cultura, ocorrem decréscimos na digestibilidade in vitro da matéria seca da silagem de milho, evento que limita a disponibilidade de alguns elementos da porção fibrosa da planta em participar da dinâmica digestiva no organismo animal. No entanto, maior processamento mecânico pode acarretar em melhoras na digestibilidade da fibra e o aumento no conteúdo de amido dos grãos torna-se um efeito compensatório desta limitação imposta pela porção fibrosa, enriquecendo a fração energética, possibilitando a obtenção de um alimento com maior valor nutritivo.

Vários trabalhos na área de terminação de bovinos de corte em confinamento foram conduzidos com o intuito de alavancar a eficiência produtiva e a qualidade do produto final (COSTA et al., 2002; NEUMANN et al., 2007; OLIVEIRA et al., 2011; PACHECO et al., 2006; RESTLE; VAZ, 2003; VAZ et al., 2012). A situação atual tem estimulado ainda mais as pesquisas que visam gerar tecnologias para incrementar a eficiência produtiva e econômica nos sistemas de produção de carne, pois desde 2004 o Brasil é considerado o maior exportador e o segundo maior produtor de carne bovina, mantendo grande parte da área do seu território com florestas preservadas (ABIEC, 2011).

O crescimento dos sistemas de confinamentos, juntamente com o aumento da produção agrícola brasileira, somam fatores que contribuem com a maior utilização de grãos na elaboração das dietas para bovinos de corte. Para potencializarmos a eficiência produtiva dos animais em confinamento, devemos prestar atenção nos fatores que tem 
influência direta sobre esta, sendo o consumo de matéria seca um dos principais coadjuvantes, este pode ser limitado ou estimulado por relações ao ambiente e por efeito direto do alimento fornecido, sendo alimentos volumosos com alta taxa de umidade, um dos principais fatores que ocasionam redução no consumo animal e, consequentemente, no seu desempenho final (ERDMAN, 1993; MERTENS, 1994). Portanto, quando colhida a lavoura de milho em estádio fenológico avançado, aliando um eficiente processamento da porção grãos, existe a possibilidade de se obter elevada qualidade de silagem, culminando em bom desempenho produtivo dos bovinos.

O objetivo do presente trabalho foi avaliar a digestibilidade in vitro da matéria seca, digestibilidade da fibra em detergente neutro (FDN) e desempenho de novilhos super precoces em sistema de confinamento utilizando silagens de milho com diferentes matérias secas e diferentes processamento dos grãos.

\section{Material e Métodos}

O trabalho foi realizado no Núcleo de Produção Animal - NUPRAN da Universidade Estadual do Centro-Oeste - UNICENTRO no município de Guarapuava - PR, situado na zona subtropical do Paraná (IAPAR, 2000), sob as coordenadas geográficas $25^{\circ} 23^{\prime} 02^{\prime \prime}$ de latitude sul e 51 29 ' $43^{\prime \prime}$ 'de longitude oeste e $1.120 \mathrm{~m}$ de altitude, em Latossolo bruno distroférrico típico, textura muito argilosa (EMBRAPA, 2006).

A implantação da cultura foi efetuada uniformemente para ambos os tratamentos aos 16 dias do mês de outubro de 2010, em sistema de plantio direto, com espaçamento entre linhas de $0,8 \mathrm{~m}$, profundidade de semeadura média de 0,04 $\mathrm{m}$ e distribuição de 5 sementes por metro linear, visando obter população final de 62.500 plantas ha $^{-1}$.
As plantas foram colhidas em diferentes estádios reprodutivos (R3 e R5) e expostas a diferentes processamento de grãos (com ou sem processamento). Durante a ensilagem, na confecção dos 16 silos, um "bag”, com peso conhecido, foi locado no perfil de cada silo, sendo estes considerados como unidades experimentais. A designação de "bag" refere-se a um saco de náilon maleável $100 \%$ poliamina, com poros de 85 micrômetros, dimensões de $12 \mathrm{~cm}$ de diâmetro e 50 $\mathrm{cm}$ de comprimento, com capacidade média de 2 $\mathrm{kg}$, com nível de compactação prévio aproximado de $350 \mathrm{~kg} \mathrm{~m}^{3-1}$ de matéria verde (material original) (NEUMANN, 2006). Os "bags" foram dispostos na porção intermediária do perfil dos silos.

Cada "bag" foi identificado, pesado individualmente vazio e novamente pesado após seu enchimento com o material original. A compactação final da massa contida nos "bags" foi efetuada pelo trator no silo, buscando a mesma compactação entre material original do "bag" e do silo.

No momento da inserção dos "bags" em cada um dos silos, paralelamente, foram coletados amostras semelhantes (homogêneas e representativas) dos materiais originais para congelamento. Com a abertura dos silos que ocorreu em média 60 dias após a ensilagem, resgatou-se as amostras de silagens contidas em cada "bag", onde uma parte na forma "in natura" foi utilizada para determinação de $\mathrm{pH}$, utilizando $9 \mathrm{~g}$ do material com $60 \mathrm{ml}$ de água destilada e deionizada, medindo o potencial hidrogenionico após 30 minutos, seguindo recomendações de Silva e Queiroz (2009). Outra parte da amostra foi pesada e pré-secada em estufa de ar forçado a $55^{\circ} \mathrm{C}$ até atingir peso constante, sequencialmente, retirada da estufa e pesada novamente para determinação do teor de matéria seca parcialmente seca (DETMANN; SOUZA; VALADARES FILHO, 2012). Os "bags" foram utilizados para realização das análises de digestibilidade in vitro da matéria seca (DIVMS) e digestibilidade da fibra em detergente neutro (DFDN). 
O experimento teve duração de 84 dias, sendo 14 dias de adaptação dos animais às dietas, instalações experimentais e iluminação noturna, que sequencialmente, passaram por 4 períodos de 21 dias de avaliação. Foram avaliados o consumo de matéria seca médio diário (CMSD), consumo de matéria seca em relação ao peso vivo (CMSP), ganho de peso médio diário (GMD) e conversão alimentar (CA) dos bovinos confinados alimentados "ad libitum", através do fornecimento de um nível fixo em $5,5 \mathrm{~kg}$ animal $^{-1}$ dia $^{-1}$, com a adição das silagens colhidas em diferentes estádios e submetidas a diferentes processamento de grãos.

As instalações foram constituídas de 16 baias individuais de confinamento, semi-cobertas, com área de $15 \mathrm{~m}^{2}(2,5 \mathrm{~m} \times 6,0 \mathrm{~m})$, possuindo um comedouro de concreto medindo $2,30 \mathrm{~m}$ de comprimento, 0,60 $\mathrm{m}$ de largura e 0,35 $\mathrm{m}$ de profundidade e um bebedouro metálico regulado por bóia automática com capacidade para 5 litros e boa vazão de reposição de água. Utilizou-se 32 novilhos inteiros, de raça Canchim, provenientes do mesmo rebanho, com idade média de 12 meses e peso vivo inicial de $365 \mathrm{~kg}$ com desvio padrão de $5 \mathrm{~kg}$, vermifugados e equilibrados por peso e condição corporal por tratamento, onde cada dois animais representaram uma unidade experimental.

As rações foram formuladas de acordo com o NRC (1996) para atenderem às exigências de ganhos diários de $1,5 \mathrm{~kg}$ de peso vivo. Na Tabela 1 encontram-se a participação de concentrado na dieta, na base seca, conforme os períodos de avaliação. A real relação volumoso:concentrado obtida com o manejo de fornecimento das rações trato, ao final, apresentou média de 53:47.

Tabela 1. Participação percentual de concentrado, expresso em porcentagem da matéria seca consumida (\% MS), nas dietas de novilhos terminados em confinamento, em função do momento da ensilagem do milho com diferentes teores de matéria seca e utilização ou não do processador de grãos.

\begin{tabular}{ccccccc}
\hline \multicolumn{2}{c}{ Sistema alimentar } & \multicolumn{5}{c}{ Períodos de confinamento } \\
\hline \multirow{2}{*}{$\begin{array}{c}\text { Estádio } \\
\text { reprodutivo }\end{array}$} & $\begin{array}{c}\text { Processamento } \\
\text { de grãos }\end{array}$ & $\begin{array}{c}1^{\circ} \text { ao } 21^{\circ} \text { dia } \\
22 / 07-11 / 08\end{array}$ & $\begin{array}{c}22^{\circ} \text { ao } 42^{\circ} \text { dia } \\
12 / 08-01 / 09\end{array}$ & $\begin{array}{c}43^{\circ} \text { ao } 63^{\circ} \text { dia } \\
02 / 09-22 / 09\end{array}$ & $\begin{array}{c}64^{\circ} \text { ao } 84^{\circ} \text { dia } \\
23 / 09-10 / 10\end{array}$ & Média \\
\cline { 2 - 6 } R3 & Com & 53,3 & 50,6 & 48,3 & 47,0 & 49,8 \\
R3 & Sem & 48,2 & 49,1 & 47,5 & 46,1 & 47,0 \\
R5 & Com & 47,0 & 45,4 & 44,0 & 43,4 & 45,0 \\
R5 & Sem & 49,1 & 45,9 & 43,9 & 41,1 & 45,0 \\
\hline \multicolumn{2}{l}{ Média \% de concentrado } & 49,4 & 47,7 & 45,9 & 44,4 & 46,7 \\
\hline
\end{tabular}

Fonte: Elaboração dos autores.

A mistura do componente concentrado da dieta, foi elaborada na fábrica de rações comerciais da Cooperativa Agrária Agroindustrial localizada no distrito de Entre Rios em Guarapuava - PR, os níveis de garantia do concentrado e das diferentes silagens estão expressos na Tabela 2.

Para avaliação bromatológica dos constituintes das dietas, coletou-se amostras que foram destinadas a estufas de ar forçado a $55^{\circ} \mathrm{C}$ até atingir peso constante, realizando-se a pesagem e obtenção da MS parcial, após realizou-se a moagem em moinho do tipo "Willey" equipado com peneira de $1 \mathrm{~mm}$ de diâmetro. Para MS total utilizou-se estufa de secagem e esterilização a $105^{\circ} \mathrm{C}$ seguindo metodologia de Silva e Queiroz (2009), proteína bruta (PB) pelo método micro Kjedahl, matéria mineral $(\mathrm{MM})$ por incineração a $550^{\circ} \mathrm{C}$ durante 
4 horas e extrato etéreo (EE) conforme técnicas descritas em AOAC (1995). Os teores de fibra em detergente neutro (FDN) foram obtidos conforme método de Van Soest, Roberttson e Lewis (1991) com a enzima $\alpha$-amilase termo-estável e de fibra em detergente ácido (FDA) segundo Goering e Van
Soest (1970). Os teores de nutrientes digestíveis totais (NDT, \%) foram estimados via equação sugerida por Bolsen (1996), onde: [NDT, \% $=87,84$ - $(0,70$ x FDA $)]$. Os nutrientes minerais foram analisados conforme metodologia descrita por Tedesco et al. (1995).

Tabela 2. Participação percentual de cada parâmetro bromatológico analisado do concentrado, silagem estádio R3 e silagem estádio R5, que foram os constituintes da dieta dos novilhos confinados.

\begin{tabular}{lccc}
\hline \multicolumn{1}{c}{ Parâmetros } & Concentrado & Silagem Estádio R3 & Silagem Estádio R5 \\
\hline Matéria Seca & 89,20 & 24,95 & 34,30 \\
Fibra em Detergente Neutro & 28,66 & 52,07 & 41,07 \\
Fibra em Detergente Ácido & 13,15 & 31,64 & 23,37 \\
Proteína Bruta & 19,00 & 6,37 & 6,14 \\
Extrato Etéreo & 3,95 & - & - \\
Nutrientes Digestíveis Totais & 78,66 & 65,69 & 71,48 \\
Matéria Mineral & 7,34 & 3,94 & 3,84 \\
Cálcio & 1,20 & 0,18 & 0,18 \\
Fósforo & 0,50 & 0,19 & 0,18 \\
Potássio & 0,77 & - & - \\
Magnésio & 0,34 & - & - \\
\hline
\end{tabular}

Fonte: Elaboração dos autores.

Os animais foram pesados no início e no fim do período experimental, com pesagens intermediárias a cada 21 dias, após jejum de sólidos de 12 horas. As variáveis relacionadas ao desempenho animal, ponderadas em 4 períodos de avaliação, constaram da mensuração do CMSD, CMSP (CMSD expresso por $100 \mathrm{~kg}$ de peso vivo), GMD, CA obtida pela relação CMSD/GMD, expressos em kg animal ${ }^{-1}$ dia $^{-}$ 1 .

O manejo alimentar foi realizado 2 vezes ao dia, às 6:00 e às 17:00 horas, e o consumo voluntário dos alimentos foi registrado diariamente por meio da pesagem da quantidade oferecida e das sobras do dia anterior. O ajuste no fornecimento dos alimentos nos diferentes tratamentos realizou-se de maneira que o fornecimento de silagem de milho foi regulado diariamente (ad libitum), considerando sobras de 5\% da matéria seca oferecida em relação à consumida, porém, a quantidade de concentrado oferecida aos animais foi constante do início ao fim do confinamento independente do nível de consumo do volumoso.

A adaptação dos animais, a quantidade do concentrado foi fornecida de forma pré-fixada ajustada em função da média de peso $(425 \mathrm{~kg}$ de peso vivo) obtida pelo peso médio de entrada (350 $\mathrm{kg}$ ) e peso alvo de saída (500 kg) esperado. Sendo assim, a suplementação de alimento concentrado foi oferecida na proporção de $1,3 \%$ do peso vivo obtido pela média do peso inicial e desejado ao final, compreendendo a quantia de 5,5 kg animal ${ }^{-1}$ dia $^{-1}$ fixa por todo o período experimental, considerando a prévia adaptação a alimentos concentrados que os animais sofreram antes da entrada no confinamento.

Durante a utilização das silagens, imediatamente após o aparecimento dos silos "bags", realizou-se 
avaliação dos mesmos, no laboratório de nutrição animal e análise de alimentos da UNICENTRO, onde este era pesado e realizado coletas para as diferentes avaliações, incluindo a DIVMS e DFDN.

A realização das análises de DIVMS e DFDN foram realizadas no Laboratório de Nutrição Animal (LANA), localizado na Universidade Estadual de Maringá (UEM). A metodologia utilizada para digestibilidade da MS foi a sugerida por Holden (1996) e metodologia para DFDN sugerida por Goering e Van Soest (1970).

$\mathrm{O}$ delineamento experimental foi inteiramente casualizado, composto por 4 tratamentos com 4 repetições, onde cada repetição constou de uma baia contendo dois novilhos, totalizando 16 unidades experimentais. Os dados das variáveis relativas ao desempenho animal foram submetidos à análise de variância com comparação de médias a 5\% de significância, pelo programa estatístico SAS (1993).

O experimento foi conduzido atendendo os princípios de bem estar animal e ética com animais experimentais. Antecipadamente, o projeto de pesquisa foi aprovado pela Comissão de Ética em Experimentação Animal da Universidade Estadual do Centro-Oeste, instituição onde foi realizado o trabalho, sob o protocolo número 029/2011.

\section{Resultados e Discussões}

Na Tabela 3 estão descritos os percentuais médios de digestibilidade "in vitro" da matéria seca e digestibilidade da fibra em detergente neutro das silagens oriundas das diferentes épocas de corte e diferentes processamentos de grãos. Pode ser observado a ocorrência de interação entre os diferentes tratamentos para todos os quesitos avaliados, sugerindo efeitos significativos na DIVMS e DFDN tanto para estádios de colheita (R3 e R5) quanto para diferentes processamentos de grãos (com ou sem).

Diferenças significativas foram observadas para o estádio de colheita R5, demonstrando uma redução na digestibilidade da matéria seca para este estádio (70,73 contra 75,34\%, respectivamente para os estádios R5 e R3), o que é esperado pois com o avançar do estádio fenológico ocorre um maior acúmulo de lignina nos tecidos vegetais, assim como a elevação linear da vitreosidade dos grãos com o avançar da maturidade, fatores os quais fazem com que a digestibilidade seja afetada, devido a limitada ação de enzimas digestoras (RUSSELL et al., 1992; PEREIRA et al., 2004). No entanto comparando-se somente as silagens que sofreram processamento, o tratamento que apresentou maior redução na DIVMS foi o que não se utilizou do acessório processador de grãos no momento da colheita da lavoura $(67,43$ contra $74,03 \%$, respectivamente para sem e com processamento), implicando uma atuação deste acessório quebrador de grãos sob a DIVMS de silagens de milho colhida em estádio R5, possivelmente justificado pelo fato de demonstrar pequena redução no tamanho das partículas da silagem e efeito sobre a integridade dos grãos, permitindo maior contato dos microrganismos fermentadores com os carboidratos de reserva, permitindo rápida queda do $\mathrm{pH}$ da silagem, interrompendo o consumo de carboidratos como amido e hemicelulose (NEUMANN et al., 2002).

Corroborando com o exposto, temos a DFDN que apresentou comportamento muito semelhante ao observado na digestibilidade da matéria seca, o qual demonstrou redução na desta fração no estádio reprodutivo R5 (52,53 contra 27,62\%, respectivamente para os estádios R3 e R5). Nesse sentido, também é possível observar que dentro do estádio R5 o fator processamento obteve alta significância para a DFDN (21,08 contra 34,16\%, para sem e com processamento respectivamente), apoiando o resultado observado para este mesmo quesito na avaliação da DIVMS.

A composição, e por consequência qualidade da FDN, está atrelada diretamente a fatores intrínsecos da planta como espécie, estádio fenológico e condições de crescimento. Devido as suas 
características físico-químicas a fração FDN tem importância que concerne a nutrição de ruminantes, pois pode influenciar diretamente o consumo dos animais, o que se reflete em seu desempenho produtivo. Desta forma, a digestibilidade da FDN pode demonstrar com mais clareza o real impacto que esta fração pode ter sobre alguns parâmetros ruminais que têm relação direta com o consumo e aproveitamento do alimento como taxa de digestão da fração fibrosa, tempo de retenção da digesta no retículo-rúmen e taxa de passagem pelo trato digestório (OLIVEIRA et al., 2011).

Tabela 3. Teores médios percentuais de digestibilidade in vitro da matéria seca (DIVMS) e digestibilidade da fibra em detergente neutro (DFDN) das silagens, em função dos estádios de maturação e processamento dos grãos.

\begin{tabular}{cccc}
\hline \multirow{2}{*}{ Processamento de grãos } & \multicolumn{2}{c}{ Silagem } & \multirow{2}{*}{ Média } \\
\cline { 2 - 2 } & Grão Pastoso, R3 & Grão Duro, R5 & 72,21 \\
Sem & DIVMS SILAGEM, \% na MS & 73,86 \\
Com & $76,99 \mathrm{aA}$ & $67,43 \mathrm{bB}$ & \\
Média & $73,69 \mathrm{aA}$ & $74,03 \mathrm{aA}$ & \\
\hline & 75,34 & 70,73 & 37,72 \\
Sem & DFDN SILAGEM, \% na MS & 42,43 \\
Com & $54,37 \mathrm{aA}$ & $21,08 \mathrm{bB}$ & \\
\hline Média & $50,70 \mathrm{aA}$ & $34,16 \mathrm{aB}$ & 27,62 \\
\hline
\end{tabular}

Na interação entre estádio reprodutivo e processamento de grãos, letras minúsculas diferentes na coluna compara o efeito do estádio reprodutivo dentro de cada processamento, enquanto que letras maiúsculas diferentes na linha compara o efeito do processamento dentro de cada estádio reprodutivo, pelo Teste $\mathrm{F}$ a $5 \%$.

Fonte: Elaboração dos autores.

Andrae et al. (2001), quando avaliando a degradabilidade in situ de silagens de milho, concluíram que o efeito combinado da colheita da lavoura de milho em dois estádios (meia linha do leite e grão cheio) juntamente com a utilização de rolos para quebra dos grãos, resultaram em uma tendência $(\mathrm{P}<0,10)$ de maior desaparecimento da matéria seca potencialmente degradável, quando comparado com a não utilização dos rolos na colhedora de forragem.

Em experimento com alimentação de vacas em lactação contendo em suas dietas silagens de milho com similares teores de FDN mas diferentes teores de digestilidade da FDN, Grant, Haddad e Moore (1995) e Dado e Allen (1996), observaram maiores consumos de matéria seca e produção de leite para as vacas que consumiram silagens com maiores coeficientes de digestibilidade da FDN. Assim, o melhoramento de plantas visando a obtenção de materiais com menor concentração de lignina e maior digestibilidade da fibra já podem ser observados, como é o caso dos híbridos de nervura marrom (bm3), no entanto, as sementes que possuem está tecnologia apresentam alto custo de aquisição limitando sua utilização (SILVA; BERNARDES, 2004).

Trabalhando com silagens de milho com diferentes teores de umidade e diferentes compactações, Senger et al. (2005) observaram que ocorreu aumento significativo na DIVMS dos níveis mais baixos de MS para os mais altos, obtendo valores de $46,7,52,1$ e $56,7 \%$ respectivamente para as silagens apresentando teores de 20, 26 e 28\% de matéria seca. Evidencia-se que todas as silagens avaliadas pelos autores apresentaram teores de matéria seca considerados baixos pela literatura, podendo ocorrer interferências nos resultados apresentados (NUSSIO et al., 1999). 
Pesce et al. (2000) estudaram o comportamento de 20 híbridos de sorgo para confecção de silagem, os autores observam média de matéria seca para os diferentes híbridos de 27,6\%, encontrando média de DIVMS de $58,6 \%$, variando de $54,1 \%$ a $63,0 \%$ entre o menor valor e maior valor de digestibilidade. Os autores justificaram a ampla variação nos resultados de DIVMS e o teor de MS pela ocorrência da colheita de todos os híbridos no mesmo dia, prejudicando o desempenho de híbridos que possuíam ciclo mais tardios.

Na Tabela 4 encontram-se descritos os valores médios para ganho médio diário (GMD) e consumo de matéria seca (CMSD), descritos em kg animal $\mathrm{dia}^{-1}$, consumo em relação ao peso vivo (CMSP) descrito em percentagem do peso vivo dos animais, e conversão alimentar (CA) sendo esta uma relação entre o consumo de matéria seca por dia e o ganho de peso médio diário apresentado pelos animais.
Pode-se observar que não houve interação significativa para CMSD, CMSP, GMD e CA entre estádio reprodutivo à colheita e processamento de grãos. No entanto, diferenças significativas $(\mathrm{P}>0,05)$ foram encontradas para silagens possuindo diferentes teores de matéria seca, sendo os animais que possuíam em sua dieta silagem de milho colhida em estádio de grão duro (R5) tiveram maior GMD (1,682 contra 1,475), CMSD (10,02 contra 9,21), CMSP (2,22 contra 2,10) e melhor CA $(6,06$ contra 6,77) comparativamente com silagem colhida no estádio de grão pastoso (R3), independente ao uso do quebrador de grãos. Sendo estes resultados atrelados a maior qualidade da silagem quando colhida em avançado estádio reprodutivo, apresentado acréscimo nos teores de amido, pela maior participação do grão no total da massa ensilada e, consequentemente, diluição nos teores de fibras deste alimento.

Tabela 4. Médias para consumo de matéria seca (CMS) expresso em kg/dia (CMSD) e em porcentagem do peso vivo (CMSDP), ganho de peso médio diário (GMD) e conversão alimentar (CA) de novilhos terminados em confinamento com silagens de milho com dois teores de matéria seca associado ao uso do processador de grãos durante a confecção da silagem.

\begin{tabular}{|c|c|c|c|}
\hline \multirow{2}{*}{ Processamento de grãos } & \multicolumn{2}{|c|}{ Estádio reprodutivo } & \multirow{2}{*}{ Média } \\
\hline & Grão pastoso, R3 & Grão duro, R5 & \\
\hline \multicolumn{4}{|c|}{ GMD, $\mathrm{kg} / \mathrm{dia}$} \\
\hline Sem & 1,379 & 1,658 & $1,519 \mathrm{a}$ \\
\hline Com & 1,570 & 1,705 & $1,638 \mathrm{a}$ \\
\hline Média & $1,475 \mathrm{~B}$ & $1,682 \mathrm{~A}$ & \\
\hline \multicolumn{4}{|c|}{$\mathrm{CMSD}, \mathrm{kg} / \mathrm{dia}$} \\
\hline Sem & 9,41 & 10,08 & $9,75 \mathrm{a}$ \\
\hline Com & 9,01 & 9,96 & $9,49 \mathrm{a}$ \\
\hline Média & $9,21 \mathrm{~B}$ & $10,02 \mathrm{~A}$ & \\
\hline \multicolumn{4}{|c|}{ CMSP, \% do PV } \\
\hline Sem & 2,13 & 2,22 & $2,18 \mathrm{a}$ \\
\hline Com & 2,06 & 2,21 & $2,14 \mathrm{a}$ \\
\hline Média & $2,10 \mathrm{~B}$ & $2,22 \mathrm{~A}$ & \\
\hline \multicolumn{4}{|c|}{$\mathrm{CA}, \mathrm{CMSD} / \mathrm{GMD}$} \\
\hline Sem & 7,35 & 6,18 & $6,77 \mathrm{a}$ \\
\hline Com & 6,19 & 5,93 & $6,06 \mathrm{~b}$ \\
\hline Média & $6,77 \mathrm{~A}$ & $6,06 \mathrm{~B}$ & \\
\hline
\end{tabular}

Médias seguidas de letras maiúsculas diferentes na linha ou seguidas de letras minúsculas diferentes na coluna, diferem entre si $(\mathrm{P}<0,05)$ pelo Teste $\mathrm{F}$ a $5 \%$.

Fonte: Elaboração dos autores. 
Quando analisado o efeito processador de grãos na confecção das silagens, independente do ponto de colheita do milho para silagem, apenas a variável CA apresentou significância estatística $(\mathrm{P}<0,05)$, sendo os valores encontrados de 6,06 e 6,77 para os tratamentos com e sem o uso do processador de grãos no momento da colheita da silagem, respectivamente. Este fato sugere a ocorrência de atuação do processador durante a confecção das silagens de milho, resultando em alteração do padrão médio de tamanho de partículas e da porcentagem de grãos inteiros na silagem, determinando maior eficiência no desempenho de bovinos terminados em confinamento, por resultar em melhoria de $10,6 \%$ na transformação da matéria seca consumida em ganho de peso e aumento de $7,2 \%$ na eficiência de ganho de peso médio diário, apesar desta última variável não ter apresentado diferenças significativas.

Sob análise numérica, os dados gerais do presente trabalho mostraram que os animais, independente da MS da silagem, tiveram maiores ganhos de peso e melhor conversão alimentar com a inclusão de silagem confeccionada com o processador de grãos, comparativamente aos animais que não receberam o tratamento do processador.

De acordo com Eifert et al. (2004), a necessidade energética de bovinos jovens em confinamento para mantença, associada ao efeito de enchimento ruminal da dieta e do desenvolvimento do rúmen é maior que para bovinos que concluíram seu crescimento, fato este que pode ajudar a justificar o fato de que animais que consumiram a silagem com maior teor de MS obtiveram melhores desempenhos perante a silagem com menor MS.

Neumann et al. (2007) ao avaliarem terminação de bovinos em sistema de confinamento utilizando silagens de milho e sorgo com diferentes níveis de concentrado na dieta em relação ao peso vivo (PV) dos animais ( 0,$8 ; 1,0$ e $1,2 \%$ do PV), evidenciaram que o GMD variou conforme o nível de concentrado, apresentando uma relação linear crescente, mostrando aumento no GMD de
0,153 kg.dia ${ }^{-1}$ frente ao aumento da inclusão de concentrado na dieta na proporção de $0,2 \%$ do peso vivo, independente do volumoso utilizado, ainda concluíram que a silagem de milho, associada há elevação na ordem de $0,2 \%$ do PV dos animais em concentrado, apresentou melhores resultados em relação a conversão alimentar do bovinos, apresentando um comportamento linear decrescente na ordem de $0,085 \mathrm{~kg}$ de MS para cada $\mathrm{kg}$ de ganho de peso.

Avaliando o consumo de matéria seca de diferentes raças zebuínas alimentadas com silagem de milho como volumoso, Ribeiro et al. (2012) observaram média geral de consumo de 8,68 kg.animal.dia ${ }^{-1}$ de MS, representando 2,29\% do peso dos bovinos. Resultado de consumo de MS superior ao descrito anteriormente foi demonstrado no presente trabalho, apresentando como média geral consumo na ordem de 9,62 kg.animal.dia 1 , no entanto quando analisados os consumos de MS em relação ao PV dos animais, percebemos que o presente trabalho apresentou consumos menores (2,16\% do PV), resultado este explicado pela diferença entre os grupamentos de bovinos utilizados nos experimento, sendo os zebuínos caracterizados por possuírem seu desenvolvimento e maturidade fisiológica tardias quando comparados aos taurinos.

\section{Conclusão}

Silagens colhidas em estádio de grão pastoso apresentaram melhores valores de digestibilidade "in vitro" da matéria seca e digestibilidade da fibra em detergente neutro, no entanto, o maior processamento da fração grãos no estádio de grão duro, possibilitou melhorias nestes fatores e na conversão alimentar dos animais, reforçando a necessidade de adequado processamento de partículas e dos grãos, quando colhida a silagem em estádio reprodutivo avançado da cultura do milho. 
A utilização da silagem de milho colhida em estádio R5 possibilitou maior desempenho animal com consequente melhor transformação da matéria seca consumida em produto.

\section{Referências}

ASSOCIAÇÃO BRASILEIRA DAS INDUSTRIAS EXPORTADORAS DE CARNE - ABIEC. São Paulo: Pecuária Brasileira, 2011. Disponível em: $<\mathrm{http}: / / \mathrm{www}$. abiec.com.br/3_pecuaria.asp>. Acesso em: 23 abr. 2012.

ANDRAE, J. G.; HUNT, C. W.; PRITCHARD, G. T.; KENNINGTON, L. R.; HARRISON, J. H.; KEZAR, W.; MAHANNA, W. Effect of hybrid, maturity and mechanical processing of corn silage on intake and digestibility by beef cattle. Journal of Animal Science, Champaign, v. 79, n. 9, p. 2268-2275, 2001.

ASSOCIATION OF OFFICIAL ANALYTICAL CHEMISTS - AOAC. Official methods of analysis. 16. ed. Washington, D. C.: AOAC, 1995. 2000 p.

BOLSEN, K. K. Silage technology. In: AUSTRALIAN MAIZE CONFERENCE, 2., 1996, Queensland. Proceedings... Queensland: Gatton College, 1996. p. 1-30.

COSTA, E. C.; RESTLE, J.; PASCOAL, L. L.; VAZ, F. N.; AlVES FILHO, D. C.; ARBOITTE, M. Z. Desempenho de novilhos red angus superprecoces, confinados e abatidos com diferentes pesos. Revista Brasileira de Zootecnia, Viçosa, MG, v. 31, n. 1, p. 129138, 2002.

DADO, R. G.; ALLEN, M. S. Enhanced intake and production of dary cows offered ensiled alfafa with higher neutral detergent fiber digestibility. Journal of Dairy Science, Savoy, v. 79, n. 3, p. 418-428, 1996.

DETMANN, E.; SOUZA, M. A.; VALADARES FILHO, S. C. Métodos para análise de alimentos. Visconde do Rio Branco: Universidade Federal de Viçosa, 2012. 214 p.

EIFERT, E. C.; RESTLE, J.; PASCOAL， L. L.; BRONDANI, I. L.; NEUMANN, M.; SILVA, J. H. S.; CARLOTTO, S. B. Bezerros de corte desmamados precocemente alimentados com silagem de triticale associada a diferentes níveis de concentrado. Revista Brasileira de Zootecnia, Viçosa, MG, v. 33, n. 6, p. 18061813, 2004. Suplemento.

EMPRESA BRASILEIRA DE PESQUISA AGROPECUÁRIA - EMBRAPA. Centro Nacional de Pesquisa de Solos. Sistema brasileiro de classificação de solos. 2. ed. Brasília: Embrapa-SPI, 2006. 306 p.
ERDMAN, R. Silage fermentation characteristics affecting feed intake. In: NATIONAL SILAGE PRODUCTION CONFERENCE, Syracuse, 1993. Proceedings... Syracuse: NRAES-67, 1993. p. 210.

GOERING, H. K.; VAN SOEST, P. J. Forage fiber analysis: apparatus reagents, procedures and some applications. Washington, D. C.: Agricultural Handbook, 1970. $379 \mathrm{p}$.

GRANT, R. J.; HADDAD, S. G.; MOORE, K. J. et al. Brown midrib sorghum silage for midlactation dairy cows. Journal of Dairy Science, Savoy, v. 78, n. 9, p. 1970-1980, 1995.

HOLDEN, L. A. Comparison of methods of in vitro dry matter digestibility for ten feeds. Journal of Dairy Science, Savoy, v. 82, n. 2, p. 1791-1794, 1996.

INSTITUTO AGRONÔMICO DO PARANÁ - IAPAR. Cartas climáticas do Paraná. Versão 1. 0. 2000. CDROM.

MERTENS, D. R. Regulation of forage intake. In: FAHEY JÚNIOR, G. C. (Ed.). Forage quality, evaluation and utilization. American Society of Agronomy. NATIONAL CONFERENCE ON FORAGE QUALITY, EVALUATION AND UTILIZATION, Madison. Anais... Madison: American Society of Agronomy, 1994. p. 450493.

NATIONAL RESEARCH COUNCIL - NRC. Nutrient requirements of domestic animals. $7^{\text {th }}$. ed. rev. Washington, D. C.: National Academy Press, 1996. 90 p.

NEUMANN, M.; RESTLE, J.; ALVES FILHO, D. C.; BERNARDES, R. A. C.; ARBOITE, M. Z.; CEDÓTES, L.; PEIXOTO, L. A. O. Avaliação de diferentes híbridos de sorgo (Sorghum bicolor, L. Moench) quanto aos componentes da planta e silagens produzidas. Revista Brasileira de Zootecnia, Viçosa, MG, v. 31, n. 1, p. 302312, 2002. Suplemento.

NEUMANN, M. Efeito do tamanho de partícula e da altura de colheita das plantas de milho (Zea mays L.) sobre perdas, valor nutritivo de silagens e desempenho de novilhos confinados. 2006. Tese (Doutorado em Zootecnia) - Curso de Pós-graduação em Zootecnia, Universidade Federal do Rio Grande do Sul, Porto Alegre.

NEUMANN, M.; SANDINI, I. E.; OST, P. R.; FALBO, M. K.; LUSTOSA, S. B. C.; PELleGRINI, L. G. Desempenho de novilhos confinados alimentados com silagens de milho ou sorgo, associadas a três níveis de concentrado. Revista Brasileira de Milho e Sorgo, Sete Lagoas, v. 6, n. 3, p. 365-378, 2007. 
NEUMANN, M.; OLIVEIRA, M. R.; ZANETTE, P. M.; UENO, R. K.; MARAFON, F.; SOUZA, M. P. Aplicação de procedimentos técnicos na ensilagem do milho visando maior desempenho animal. In: SIMPÓSIO SOBRE PRODUÇÃO E UTILIZAÇÃO DE FORRAGENS CONSERVADAS, 4., 2011, Maringá. Anais... Maringá: [s.n], 2011.p. 292.

NUSSIO, L. G.; MANZANO, R. P. Silagem de milho. In: SIMPÓSIO SOBRE NUTRIÇÃO DE BOVINOS: ALIMENTAÇÃO SUPLEMENTAR, 7., 1999, Piracicaba. Anais... Piracicaba: FEALQ, 1999. p. 27-46.

OLIVEIRA, M. R.; NEUMANN, M.; MENDES, M. C.; FARIA, M. V.; NERI, J. Resposta econômica na terminação de novilhos confinados com silagens de milho (Zea mays L.), em diferentes estádios de maturação, associadas a dois níveis de concentrado na dieta. Revista Brasileira de Milho e Sorgo, Sete Lagoas, v. 10, n. 2, p. 87-95, 2011.

PACHECO, P. S.; RESTLE, J.; VAZ, F. N.; FREITAS, A. K.; PADUA, J. T.; NEUMANN, M.; ARBOITTE, M. Z. Avaliação econômica da terminação em confinamento de novilhos jovens e superjovens de diferentes grupos genéticos. Revista Brasileira de Zootecnia, Viçosa, MG, v. 35, n. 1, p. 309-320, 2006.

PEREIRA, M. N.; VON PINHO, R. C.; BRUNO, R. G. S.; CASTELINE, G. A. Ruminal degradability of hard or soft texture corn grain at three maturity stages. Scientia Agricola, Piracicaba, v. 61, n. 4, p. 358-363, 2004.

PESCE, D. M. C.; GONÇALVES, L. C.; RODRIGUES, N. M.; BORGES, I.; RODRIGUES, J. A. S. Porcentagem, perda e digestibilidade in vitro da matéria seca das silagens de 20 genótipos de sorgo. Arquivo Brasileiro de Medicina Veterinária e Zootecnia, Belo Horizonte, v. 52, n. 3, p. 258-272, 2000.

RESTLE, J.; VAZ, F. N. Eficiência e qualidade na produção de carne bovina. In: REUNIÃO ANUAL DA SOCIEDADE BRASILEIRA DE ZOOTECNIA, 40., 2003, Santa Maria. Anais... Santa Maria: Sociedade Brasileira de Zootecnia, 2003. CD ROM.

RIBEIRO, J. S.; LADEIRA, M. M.; MACHADO NETO, O. R.; CAMPOS, F. R. Consumo alimentar e sua predição pelos sistemas, NRC, CNCPS e BR-Corte, para tourinhos zebuínos confinados. Revista Ciência Agronômica, Fortaleza, v. 43, n. 4, p. 802-810, 2012.
RUSSELL, J. R.; IRLBECK, N. A.; HALLAUER, A. R.; BUXTON, D. R. Nutritive value and ensiling characteristics of maize herbage as influenced by agronomic factors. Animal Feed Science and Technology, Amsterdam, v. 38, n. 2, p. 11-24, 1992.

SENGER, C. C. D.; MÜHLBACH, P. R. F.; BONNECARRÈRE SANCHEZ, L. M.; PERES NETTO, D.; LIMA, L. D. Composição e digestibilidade 'in vitro' de silagens de milho com distintos teores de umidade e níveis de compactação. Ciência Rural, Santa Maria, v. 35, n. 6, p. 1393-1399, 2005.

STATISTICAL ANALYSIS SYSTEM INSTITUTE - SAS. SAS INSTITUTE. SAS/STAT user's guide: statistics. 4. ed. Version 6. Cary, North Caroline, 1993. v. 2, $943 \mathrm{p}$.

SILVA, D. J.; QUEIROZ, A. C. Análise de alimentos, métodos químicos e biológicos. 3. ed. 4. reimp. Universidade Federal de Viçosa, 2009. 235 p.

SILVA, Z. F.; BERNARDES, T. F. Concentração $e$ digestibilidade da FDN da silagem sobre o desempenho de novilhos. [S.1. s.n.], 2004. Disponível em < http:// www.milkpoint.com.br/radar-tecnico/conservacaode-forragens/concentracao-e-digestibilidade-da-fdnda-silagem-sobre-o-desempenho-de-bovinos-21211n. aspx $>$. Acesso em: 13 dez. 2012.

TEDESCO, M. J.; GIANELlO, C.; BISSANI, C. A.; BOHNEN, H.; VOLKWEISS, S. J. Análises de solo, plantas e outros materiais. 2. ed. Porto Alegre: Universidade Federal do Rio Grande do Sul, 1995. 174 p. (Boletim técnico, n. 5).

VAN SOEST, P. J.; ROBERTTSON, J. B.; LEWIS, B. A. Methods for dietary fiber, neutral detergent fiber, and nonstarch polysaccharides in relation to animal nutrition. Journal of Dairy Science, Savoy, v. 74, n. 2, p. 35833597, 1991.

VAZ, F. N.; FLORES, J. L. C.; VAZ, R. Z.; PASCOAL, L. L.; ÁVILA, M. M. Características de carcaça e biometria testicular de machos bovinos superjovens não castrados de diferentes grupos genéticos. Ciência Animal Brasileira, Goiânia, v. 13, n. 3, p. 306-314, 2012. 
